\title{
The Risk Factors of High Blood Pressure among Young Adults in the Tujia-Nationality Settlement of China
}

\author{
Xiaoli Liu, ${ }^{1,2}$ Zheng Xiang, ${ }^{1}$ Xiangrong Shi, ${ }^{2}$ Hannah Schenck, ${ }^{2}$ \\ Xinfeng $\mathrm{Yi}^{3}{ }^{3}$ Rong Ni, ${ }^{4}$ and Chaoneng Liu ${ }^{1}$ \\ ${ }^{1}$ PE Department of Hubei University for Nationalities, Enshi, Hubei, China \\ ${ }^{2}$ Institute of Cardiovascular \& Metabolic Disease, University of North Texas Health Science Center, Fort Worth, TX, USA \\ ${ }^{3}$ National Stadium of Enshi Autonomous Prefecture, Enshi, Hubei, China \\ ${ }^{4}$ The Central Hospital of Enshi Autonomous Prefecture, Enshi, Hubei, China
}

Correspondence should be addressed to Zheng Xiang; xiang_zheng2016@163.com

Received 18 May 2017; Revised 13 July 2017; Accepted 27 July 2017; Published 28 August 2017

Academic Editor: Giulio Arcangeli

Copyright (C) 2017 Xiaoli Liu et al. This is an open access article distributed under the Creative Commons Attribution License, which permits unrestricted use, distribution, and reproduction in any medium, provided the original work is properly cited.

\begin{abstract}
Demographics questionnaires, and fitness tests were utilized to identify the risk factors of hypertension among younger adults in the years 2005, 2010, and 2014 in China's southwest province of Hubei. The results demonstrated that the prevalence of hypertension was higher between 2011 and 2014 among the young people in this area. The main risk factors of developing hypertension were found to be sex (as man), individuals over 40 years old, blue collar employees who worked in rural areas, overweight/obesity, and those with the low CRF.
\end{abstract}

\section{Background}

Hypertension is associated with increased risks of stroke, ischemic heart disease [1], heart failure, kidney disease [2], and premature mortality [3]. In China, the prevalence of hypertension among adults aged 18 years and older is substantial [4]. While more common in the older population, an increasing incidence in the younger population is being observed [5]. However, young adults meeting hypertension diagnostic criteria have a lower prevalence of a hypertension diagnosis than middle-aged and older adults [6]. So identifying young individuals who present with a greater risk for developing hypertension may help target public health prevention efforts.

The Tujia-Nationality settlement is the most poverty stricken area in the southwest Hubei province of China, though the implementation of highway and railway systems has rapidly improved the economy from 2011 to 2014. In 2005, the average salary of white collar and blue collar workers in urban areas was $\$ 1910$ and $\$ 1860$ per year, compared to $\$ 1260$ per year that was earned by blue collar workers in rural areas. In 2010, the average salary of white collar workers and blue collar workers in urban areas was $\$ 4180$ and $\$ 3480$ per year, compared to $\$ 2430$ per year that was earned by blue collar workers in rural areas. Finally, in 2014, the average salary of white collar and blue collar workers in urban areas increased to $\$ 7000$ and $\$ 5900$ per year, respectively, compared to the $\$ 3300$ per year that was earned by blue collar workers in rural areas. Young people encounter intense pressure regarding any changes in the economy, which is a main factor of many chronic diseases. However, to our knowledge, few studies focus on the changes of chronic diseases on the young people in this area, particularly hypertension. Our study analyzed blood pressure data in the years 2005,2010 , and 2014 to describe the predominant risk factors associated with hypertension within this area's younger population.

\section{Material and Methods}

2.1. Study Population. This study consisted of 3 crosssectional surveys in the years 2005, 2010, and 2014, and it was designed to investigate the risk factors of hypertension in the southwest Hubei province of China. A total of 4,120 20-44year-old young adults (age $=31.8 \pm 7.2$ years) men and women 
TABLE 1: Classification criteria of cardiorespiratory fitness (CRF).

\begin{tabular}{|c|c|c|c|c|c|c|}
\hline \multirow{2}{*}{ Age (yrs) } & \multicolumn{2}{|c|}{ Low } & \multicolumn{2}{|c|}{ Median } & \multicolumn{2}{|c|}{ High } \\
\hline & Female & Male & Female & Male & Female & Male \\
\hline $20-24$ & $\leq 46.1$ & $\leq 46.1$ & $\geq 46.2, \leq 58.0$ & $\geq 46.2, \leq 58.0$ & $\geq 58.1$ & $\geq 58.1$ \\
\hline $25-29$ & $\leq 46.8$ & $\leq 46.1$ & $\geq 46.9, \leq 59.1$ & $\geq 46.2, \leq 58.3$ & $\geq 59.2$ & $\geq 58.4$ \\
\hline $30-34$ & $\leq 47.0$ & $\leq 46.1$ & $\geq 47.1, \leq 59.9$ & $\geq 46.2, \leq 58.3$ & $\geq 60.0$ & $\geq 58.4$ \\
\hline $35-39$ & $\leq 46.8$ & $\leq 46.1$ & $\geq 46.9, \leq 60.3$ & $\geq 46.2, \leq 58.7$ & $\geq 60.4$ & $\geq 58.8$ \\
\hline $40-44$ & $\leq 46.8$ & $\leq 46.5$ & $\geq 46.9, \leq 61.5$ & $\geq 46.6, \leq 59.9$ & $\geq 61.6$ & $\geq 60.0$ \\
\hline
\end{tabular}

( $n=1081$ in 2005, $n=1461$ in 2010, and $n=1578$ in 2014) participated in this study. All participants were from the same Tujia settlement area in Hubei province of China.

2.2. Methods. The testing was comprised of two parts: a demographics questionnaire and a comprehensive physical fitness evaluation. Questionnaires inquired about participants' age, nationality, gender, urban versus rural location, employment classification, and the highest level of completed education. Fitness testing included measurements for blood pressure, height, weight, vital-lung capacity, sidestep test, standing vertical jump, sit-and-reach, grip strength, single leg stance test, reaction time, push-ups (men), and sit-ups (women).

All testing were performed in a gymnasium in July and August of the testing year $(2005,2010$, and 2014). The study subjects first completed a questionnaire. Then following a 20 min rest, trained physicians measured subjects' blood pressure using a mercury sphygmomanometer. The measurements were made in triplicate within 10 min interval with the subjects in the seated position. Arterial hypertension was defined as systolic blood pressure $\geq 140 \mathrm{mmHg}$ or diastolic $\geq$ $90 \mathrm{mmHg}$ or current treatment with antihypertensive drugs.

The cardiorespiratory fitness (CRF) was tested using the sidestep test (TDK-2 intelligent apparatus, Ningbo Jingbei Tiandikuan Electronic Product Manufacturer, China). Man subjects used a $40 \mathrm{~cm}$ high footstep and woman subjects used a $35 \mathrm{~cm}$ high footstep to perform the up-and-down movement. Every subject performed up-and-down movements for about 3 minutes (90 repetitions) in rhythm to music. After the subject sat down, a finger clip was placed on the subject's middle finger from which pulse rate was displayed on the screen and recorded. Pulse rate readings were taken 3 separate times after the completion of the sidestep exercise: between 1 minute to 1 minute 30 seconds; 2 minutes to 2 minutes 30 seconds; and 3 minutes 30 seconds. The sidestep test index was calculated from the duration of up-and-down movements (in seconds) multiplied by 100 divided by the sum of 3 pulse rate readings. Table 1 shows the classification criteria of the index as CRF according to the Citizen Physical Health Standard established by Ministry of Education of China and the General Administration of Sport of China [7].

Next we measured the subjects' height, weight, vitallung capacity, sidestep test, standing vertical jump, sit-andreach, grip strength, single leg stance test, reaction time, push-ups (male), and sit-ups (female). All of the testing apparatuses were made by the Shenzheng Hengkang Jiaye
Limited Company, China. When the subjects were ready, the testers pressed the button to initiate the beginning of the test.

All physical fitness measurements and scoring criteria were classified according to the Citizen Physical Health Standard established by Ministry of Education of China and the General Administration of Sport of China [7]. Each category we measured had an acceptable value range; if the total of these results fell within this range they were labeled as "pass," while those that did not were labeled as "fail" [7].

Body mass index (BMI) was calculated from weight (in kilograms)/height ${ }^{2}$ (in meter). The BMI was classified into four levels: $<25.0$ as normal weight, 25.0 29.9 as overweight, and $\geq 30.0$ as obesity.

2.3. Statistical Analysis. All statistical analyses were performed using the SPSS for Windows software package (version 18; SPSS Inc., Chicago, IL, USA). Descriptive statistics were obtained first and categorical variables were presented as the number of people (\%). Collinearity diagnostics were performed prior to further statistical analysis. A binary unconditional logistic regression model was used for our analysis of the independent effects of each variable. Potential risk factors included testing time, age, nationality, gender, urban versus rural location, employment classification, education level, BMI, CRF, and physical test scores. The dependent factor was "whether the subject is hypertensive" and retained methods used a forward step-by-step approach. All variables significant at $P<0.05$ were reserved in the final model.

\section{Result}

3.1. The Changes of Prevalence of Hypertension, BMI, and CRF from 2005 to 2014. Of the 4120 participants, 554 of the 4120 young adults were classified as hypertensive, giving an overall prevalence of hypertension was $13.4 \%$. From Figure 1, the prevalence of hypertension was lower at $10.6 \%$ in 2005 and $8.2 \%$ in 2010 before doubling to $20.2 \%$ by 2014 . At the same time, the incidence of overweight and obesity was $15.1 \%$ and $0.6 \%$ in 2005 , and they reached $18.5 \%$ and $2.5 \%$ in 2010 and $22.5 \%$ and $2.9 \%$ in 2014 , respectively. However, the percentages of high CRF, median CRF, and low CRF were $50.6 \%, 49.4 \%$, and $0 \%$ in 2005 , and they reached $51.4 \%, 43.6 \%$, and $5 \%$ in 2010 , respectively; they were $47.5 \%, 47.7 \%$, and $4.9 \%$ in 2014 , respectively.

3.2. Prevalence and Distribution of Hypertension. There were differences in the occurrence of hypertension among different age groups, with the likelihood increasing exponentially with 


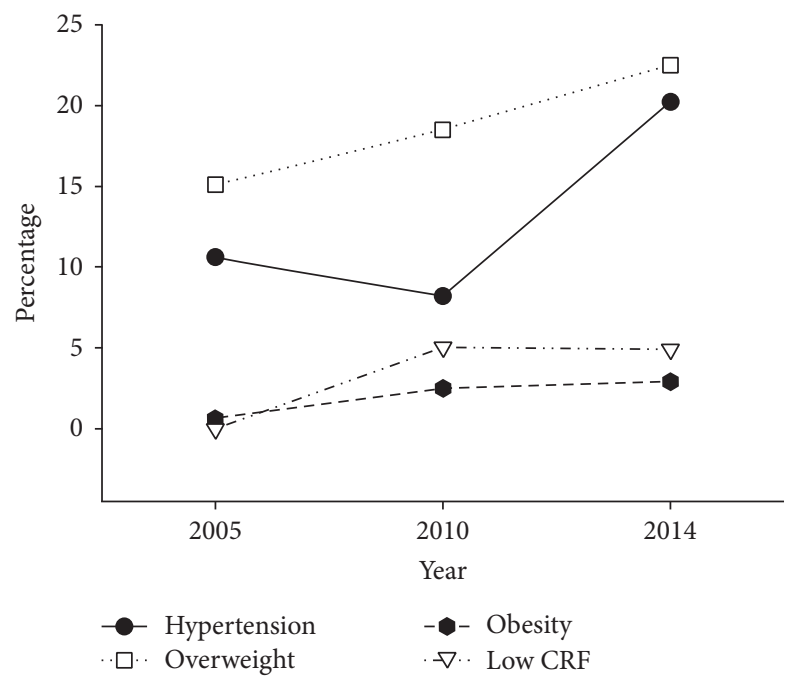

FIGURE 1: The changes of prevalence of hypertension, BMI, and CRF from 2005 to 2014. $\mathrm{BMI}=$ body mass index and CRF = cardiorespiratory fitness.

age: $8.9 \%$ among $20-24$-year-olds, $10.2 \%$ among $25-29$-yearolds, $12.3 \%$ in $30-34$-year-olds, $14.0 \%$ among $35-39$-yearolds, and $22.2 \%$ among 40-44-year-olds. The prevalence was higher among men at $17.6 \%$ compared to women at $9.4 \%$ and higher in rural residents at $15.3 \%$, compared to urban residents at $12.6 \%$.

In regard to occupation, the frequency of hypertension was highest among white collar workers at $18.0 \%$ and lowest among blue collar workers in urban areas at $11.3 \%$. By level of highest schooling attained, hypertension was highest among participants with a primary school or a middle school education at $15.6 \%$, followed by those with high school education at $13.3 \%$, and university/professional education at $10.9 \%$. Hypertension was also higher in participants with a higher BMI (42.2\% of those classified as obesity displayed hypertension). By CRF levels, prevalence was highest among participants who had the low fitness of $25.2 \%$, followed by median fitness of $15.1 \%$ and high fitness of $10.5 \%$. Hypertension was higher among individuals who failed the physical test at $15.6 \%$ compared to those who passed the test at $12.3 \%$. The distribution of hypertension by the various participant characteristics is summarized in Table 2.

3.3. Risk Factors Associated with Hypertension in Binary Logistic Regression Analysis. Table 3 shows the five risk factors associated with developing hypertension. The overall risk of hypertension was the highest in the year 2014; when compared to the same-aged individuals, this risk stood at $49.9 \%$ in 2005 and $68 \%$ in 2010 . The risk of hypertension increased with the age. Compared to the $40-44$ age group, the risk of hypertension decreased $58.9 \%, 59.7 \%, 51.0 \%$, and $44.6 \%$ in 20-24, 25-29, 30-34, and 35-39 age groups, respectively. Men displayed a $49.5 \%$ higher risk of hypertension compared to women. Blue collar workers in rural areas had a 1.739-fold (95\% CI, 1.258-2.403; $P=0.001$ ) risk of hypertension compared to blue collar workers in urban areas. CRF was inversely related to hypertension; those with the low level of CRF had a 2.914-fold risk of hypertension (95\% CI, 1.877-4.526; $P=0.001)$, and people with a low level of CRF had a 1.238fold risk of hypertension (95\% CI, 1.004-1.528; $P=0.046$ ). Weight, however, was directly related to hypertension; the obesity and overweight had a 6.265-fold and 2.325-fold risk of hypertension compared to normal weight individuals.

\section{Discussion}

This study indicated that the prevalence of hypertension among young adults within the Tujia settlement suddenly increased from 2011 to 2014 . Remarkably, just $6.5 \%$ of the hypertensive individuals were conscious of their chronic disease. For these young adults the main risk factors of developing hypertension were found to be sex (as man), blue collar workers in rural areas, age over 40 years old, overweight/obesity, and those with low CRF.

We found the prevalence of hypertension suddenly increased from $8.2 \%$ in 2010 to $20.2 \%$ in 2014, which was even higher than the $6.8 \%$ found within the same American age group between 2011 and 2012 [8]. It was a special time for this area in 2010-2014, because the highway and train line had their first routes in 2009 and 2010, leading to rapid development of the local economy. However, healthy lifestyles and health education did not progress at the same pace. The convenience of transport and the development of the Internet made more people opt for a sedentary life [9]. Excessive intake of fat foods led to excess calories and obesity [10]. The CRF, overweight, and obesity increased from 2005 to 2014 (Figure 1), which led to the increase of chronic disease. What made the problem even worse was that just $6.5 \%$ hypertensive people knew they had hypertension. So the people in this place must have regular physical examination and necessary health education.

Men have greater levels of oxidative stress than women [11], so they are thus more likely to have oxidative stressinduced increases in their blood pressure [12]. In our study among young adults, men had a higher risk of hypertension, which was consistent with other researches [13]. Because the targeting people were only young adults in this study, women in this area had a higher risk of hypertension once they reached middle age [14].

Since the 1980s, work related stressors have become recognized as significant elements for developing cardiovascular disease and hypertension [15]. Lower socioeconomic status workers (variously defined by education, income, or occupation) have been found to have higher age-adjusted mean systolic blood pressure (by $2-3 \mathrm{~mm} \mathrm{Hg}$ ) or prevalence of hypertension than employees in higher socioeconomic status groups [16]. Our data found blue collar workers in rural areas had a 1.739 -fold (95\% CI, 1.258-2.403; $P=0.001$ ) risk of hypertension compared to blue collar workers in urban areas. Because of the lack of health knowledge and medical care, blue collar workers in rural areas are unaware or lack the resources to prevent chronic disease and form healthier, more sustainable lifestyles [17].

Our study found that those in the 40-44 age group people had the highest risk of hypertension. As the human body 
TABLE 2: Demographics characteristics of young adults in Tujia-Nationality settlement in China, $N=4120$.

\begin{tabular}{|c|c|c|c|}
\hline Variable/category & Normal (\%) & Hypertension (\%) & Total \\
\hline Awareness & 4084 (99.1) & $36(0.9)$ & 4120 \\
\hline \multicolumn{4}{|l|}{ Test time (yr) } \\
\hline 2005 & $966(89.4)$ & $115(10.6)$ & 1081 \\
\hline 2010 & $1341(91.8)$ & $120(8.2)$ & 1461 \\
\hline 2014 & $1259(79.8)$ & $319(20.2)$ & 1578 \\
\hline \multicolumn{4}{|l|}{ Age (yrs) } \\
\hline $20-24$ & $762(91.1)$ & $74(8.9)$ & 836 \\
\hline $25-29$ & $769(89.8)$ & $87(10.2)$ & 836 \\
\hline $30-34$ & $733(87.7)$ & $103(12.3)$ & 836 \\
\hline $35-39$ & $669(86.0)$ & $109(14.0)$ & 778 \\
\hline $40-44$ & $633(77.8)$ & $181(22.2)$ & 814 \\
\hline \multicolumn{4}{|l|}{ Nationality } \\
\hline Han & $2115(85.5)$ & $358(14.5)$ & 2473 \\
\hline Tujia & $1451(88.1)$ & $196(11.9)$ & 1647 \\
\hline \multicolumn{4}{|l|}{ Sex } \\
\hline Males & $1673(82.4)$ & $358(17.6)$ & 2031 \\
\hline Females & $1893(90.6)$ & $196(9.4)$ & 2089 \\
\hline \multicolumn{4}{|l|}{ Urban-rural } \\
\hline Rural & $1116(84.7)$ & $202(15.3)$ & 1318 \\
\hline Urban & $2450(87.4)$ & $352(12.6)$ & 2802 \\
\hline \multicolumn{4}{|l|}{ Employment classification } \\
\hline Blue collar workers in rural area & $1116(84.7)$ & $202(15.3)$ & 1318 \\
\hline Blue collar workers in urban area & $2025(88.7)$ & $259(11.3)$ & 2284 \\
\hline White collar workers & $425(82.0)$ & $93(18.0)$ & 518 \\
\hline \multicolumn{4}{|l|}{ Education } \\
\hline Primary school & $313(84.4)$ & $58(15.6)$ & 371 \\
\hline Middle school & $1078(84.4)$ & $199(15.6)$ & 1277 \\
\hline High school & $1000(86.7)$ & $153(13.3)$ & 1153 \\
\hline College & $1175(89.1)$ & $144(10.9)$ & 1319 \\
\hline \multicolumn{4}{|l|}{$\mathrm{BMI}^{\mathrm{a}}$} \\
\hline Normal weight & $2910(89.9)$ & $326(10.1)$ & 3236 \\
\hline Overweight & $599(76.0)$ & $189(24.0)$ & 788 \\
\hline Obesity & $52(57.8)$ & $38(42.2)$ & 90 \\
\hline \multicolumn{4}{|l|}{$\mathrm{CRF}^{\mathrm{b}}$} \\
\hline High & $1804(89.5)$ & $212(10.5)$ & 2016 \\
\hline Median & $1607(84.9)$ & $286(15.1)$ & 1893 \\
\hline Low & $110(74.8)$ & $37(25.2)$ & 147 \\
\hline \multicolumn{4}{|l|}{ Physical test } \\
\hline Pass & $2468(87.7)$ & $347(12.3)$ & 2815 \\
\hline Fail & $1006(84.4)$ & $186(15.6)$ & 1192 \\
\hline
\end{tabular}

${ }^{\mathrm{a}} \mathrm{BMI}=$ body mass index and ${ }^{\mathrm{b}} \mathrm{CRF}=$ cardiorespiratory fitness.

ages it becomes less responsive to stimuli, thus making older persons display less sympathetic nervous system upregulation than is seen in younger individuals [17]. Our study demonstrated an age of 40 years was the threshold of the higher hypertensive risk.

The worldwide epidemic of excess body weight including obesity is associated with the increased prevalence of cardiovascular dangers. Obesity is linked to increased sympathetic nervous system activation and increased renin release, which are thought to contribute to hypertension development in obese individuals [18]. Our data found the obese and overweight people had 6.265-fold and 2.325-fold risk of hypertension compared normal weight people. Because obesity is the main risk factor of developing hypertension, maintaining a standard weight is the most effective way to prevent hypertension for young adults in this area.

A higher level of CRF significantly attenuated the rise in blood pressure over the lifespan. Thus, the examination of 
TABLE 3: Risk factors associated with hypertension in binary logistic regression analysis.

\begin{tabular}{|c|c|c|c|c|c|c|c|}
\hline \multirow{2}{*}{ Risk factors } & & \multirow{2}{*}{$B$} & \multirow{2}{*}{ SE } & \multirow{2}{*}{$P$} & \multirow{2}{*}{ OR } & \multicolumn{2}{|c|}{$95 \% \mathrm{CI}$ for OR } \\
\hline & & & & & & Lower & Upper \\
\hline \multirow{3}{*}{ Test time } & 2014 & & & & & & \\
\hline & 2005 & -.691 & .134 & .000 & .501 & .385 & .652 \\
\hline & 2010 & -1.141 & .132 & .000 & .320 & .247 & .414 \\
\hline \multirow{5}{*}{ Age (yrs) } & $40-44$ & & & & & & \\
\hline & $20-24$ & -.890 & .164 & .000 & .411 & .298 & .566 \\
\hline & $25-29$ & -.909 & .156 & .000 & .403 & .297 & .547 \\
\hline & $30-34$ & -.714 & .149 & .000 & .490 & .366 & .656 \\
\hline & $35-39$ & -.590 & .146 & .000 & .554 & .417 & .737 \\
\hline Sex & Women & -.683 & .104 & .000 & .505 & .412 & .619 \\
\hline \multirow{3}{*}{ Employment classification } & Blue collar workers in urban area & & & & & & \\
\hline & Blue collar workers in rural area & .553 & .165 & .001 & 1.739 & 1.258 & 2.403 \\
\hline & White collar workers & .311 & .166 & .060 & 1.365 & .987 & 1.888 \\
\hline \multirow{3}{*}{$\mathrm{CRF}^{\mathrm{b}}$} & High & & & & & & \\
\hline & Low & 1.070 & .225 & .000 & 2.914 & 1.877 & 4.526 \\
\hline & Median & .214 & .107 & .046 & 1.238 & 1.004 & 1.528 \\
\hline \multirow{4}{*}{$\mathrm{BMI}^{\mathrm{a}}$} & Normal weight & & & & & & \\
\hline & Obesity & 1.835 & .242 & .000 & 6.265 & 3.896 & 10.072 \\
\hline & Overweight & .844 & .111 & .000 & 2.325 & 1.870 & 2.892 \\
\hline & Constant & -.591 & .231 & .011 & .554 & & \\
\hline
\end{tabular}

${ }^{\mathrm{a}} \mathrm{BMI}=$ body mass index and ${ }^{\mathrm{b}} \mathrm{CRF}=$ cardiorespiratory fitness.

serial changes in CRF as it relates to incidental hypertension is of considerable interest [19]. Recent findings from animal studies suggest aerobic exercise may prevent increases in blood pressure through beneficial alterations in insulin sensitivity and autonomic nervous system function [20]. Several previous studies have reported the associations between changes in CRF over time and the risk of developing future hypertension. In a Finnish cohort of 163 high-risk males, fitness was inversely associated with carotid intimal-media thickness [21]. Further, the Kuopio Ischemic Heart Disease Risk Factor Study evaluated 854 men with baseline $\mathrm{VO}_{2}$ max testing and found that fitness was associated with slower progression of carotid atherosclerosis by high-resolution Bmode ultrasonography at baseline and at an average of 4.2 years later [22]. Our results found the increase in CRF caused a decrease in the risk of hypertension. The hypertension was higher among people who failed the physical test at $15.6 \%$ compared to the ones who passed the test at $12.3 \%$. However, it was not included as the risk factor in the logistic model, suggesting that the CRF or aerobic fitness was a more important predictor than the physical fitness in preventing hypertension.

In the present study, we were unable to find a correlation between hypertension and some of the factors that have often been associated with hypertension, such as education [23] and nationalities [24]. This indicates that there must be other risk factors of fundamental importance for hypertension in this area, other than those analyzed here, such as BMI, CRF, employment classification, and sex.

\section{Conclusion}

The prevalence of hypertension among the young Tujia population was higher during the years of 2011-2014. The main risk factors for developing chronic elevated blood pressure were found to be sex (as man), blue collar workers in rural areas, overweight/obesity, individuals over 40 years of age, and those with low CRF.

\section{Conflicts of Interest}

The authors declared no potential conflicts of interest with respect to the research, authorship, and/or publication of this article.

\section{Acknowledgments}

The authors thank their volunteer subjects for their cheerful cooperation during the study. Funding for Xiaoli Liu was provided by social science funding from Hubei Provincial Department of Education (Q15d072), China.

\section{References}

[1] F. Rodriguez, L. S. Hicks, and L. Lápez, "Association of acculturation and country of origin with self-reported hypertension and diabetes in a heterogeneous Hispanic population," BMC Public Health, vol. 12, no. 1, article no. 768, 2012.

[2] D. Guwatudde, J. Nankya-Mutyoba, R. Kalyesubula et al., "The burden of hypertension in sub-Saharan Africa: A four-country 
cross sectional study," BMC Public Health, vol. 15, no. 1, article no. 2546, 2015.

[3] W. A. N. Kumara, T. Perera, M. Dissanayake, P. Ranasinghe, and G. R. Constantine, "Prevalence and risk factors for resistant hypertension among hypertensive patients from a developing country," BMC Research Notes, vol. 6, no. 1, article no. 373, 2013.

[4] X. Xu, J. Byles, Z. Shi, P. McElduff, and J. Hall, "Dietary pattern transitions, and the associations with BMI, waist circumference, weight and hypertension in a 7-year follow-up among the older Chinese population: A longitudinal study," BMC Public Health, vol. 16, no. 1, article no. 743, 2016.

[5] T. De Venecia, M. Lu, and V. M. Figueredo, "Hypertension in young adults," Postgraduate Medicine, vol. 128, no. 2, pp. 201207, 2016.

[6] H. M. Johnson, C. T. Thorpe, C. M. Bartels et al., "Undiagnosed hypertension among young adults with regular primary care use," Journal of Hypertension, vol. 32, no. 1, pp. 65-74, 2014.

[7] Adults Physical Health Standard, Ministry of Education of China and General Administration of Sport of China, Beijing, China, 2008.

[8] T. Nwankwo, S. S. U. Yoon, V. Burt, and Q. Gu, "Hypertension among adults in the United States: national health and nutrition examination survey, 2011-2012," NCHS Data Brief, no. 133, pp. 18, 2013.

[9] J. Zhang and J. Chaaban, "The economic cost of physical inactivity in China," Preventive Medicine, vol. 56, no. 1, pp. 7578, 2013.

[10] B. Zhang, F. Y. Zhai, S. F. Du, and B. M. Popkin, "The China Health and Nutrition Survey, 1989-2011," Obesity Reviews, vol. 15, supplement 1, pp. 2-7, 2014.

[11] A. Lopez-Ruiz, J. Sartori-Valinotti, L. L. Yanes, R. Iliescu, and J. F. Reckelhoff, "Sex differences in control of blood pressure: role of oxidative stress in hypertension in females," American Journal of Physiology: Heart and Circulatory Physiology, vol. 295, no. 2, pp. H466-H474, 2008.

[12] N. B. Ojeda, B. S. Hennington, D. T. Williamson et al., "Oxidative stress contributes to sex differences in blood pressure in adult growth-restricted offspring," Hypertension, vol. 60, no. 1, pp. 114-122, 2012.

[13] M. A. Zimmerman and J. C. Sullivan, "Hypertension: what's sex got to do with it?" Physiology, vol. 28, no. 4, pp. 234-244, 2013.

[14] E. G. Katz, J. Stevens, K. P. Truesdale, J. Cai, and K. E. North, "Interactions between obesity, parental history of hypertension, and age on prevalent hypertension: The People's Republic of China study," Asia-Pacific Journal of Public Health, vol. 24, no. 6, pp. 970-980, 2012.

[15] P. A. Landsbergis, A. V. Diez-Roux, K. Fujishiro et al., "Job strain, occupational category, systolic blood pressure, and hypertension prevalence the multi-ethnic study of atherosclerosis," Journal of Occupational and Environmental Medicine, vol. 57, no. 11, pp. 1178-1184, 2015.

[16] N. L. Keenan and K. A. Rosendorf, "Prevalence of hypertension and controlled hypertension-United States, 2005-2008," Morbidity and Mortality Weekly Report, vol. 60, no. 1, pp. 94-97, 2011.

[17] L. Cohen, G. C. Curhan, and J. P. Forman, "Influence of age on the association between lifestyle factors and risk of hypertension," Journal of the American Society of Hypertension, vol. 6, no. 4, pp. 284-290, 2012.

[18] D. Xu, H. Wang, S. Chen et al., "Aerobic exercise training improves orthostatic tolerance in aging humans," Medicine and Science in Sports and Exercise, vol. 49, no. 4, pp. 728-735, 2017.
[19] S. Y. Jae, S. Kurl, B. A. Franklin, and J. A. Laukkanen, "Changes in cardiorespiratory fitness predict incident hypertension: a population-based long-term study," American Journal of Human Biology, vol. 29, no. 3, Article ID e22932, 2017.

[20] I. C. Moraes-Silva, C. Mostarda, E. Dias Moreira et al., "Preventive role of exercise training in autonomic, hemodynamic, and metabolic parameters in rats under high risk of metabolic syndrome development," Journal of Applied Physiology, vol. 114, no. 6, pp. 786-791, 2013.

[21] R. Rauramaa, T. Rankinen, P. Tuomainen, S. Väisänen, and M. Mercuri, "Inverse relationship between cardiorespiratory fitness and carotid atherosclerosis," Atherosclerosis, vol. 112, no. 2, pp. 213-221, 1995.

[22] T. A. Lakka, J. A. Laukkanen, R. Rauramaa et al., "Cardiorespiratory fitness and the progression of carotid atherosclerosis in middle-aged men," Annals of Internal Medicine, vol. 134, no. 1, pp. 12-20, 2001.

[23] J. Li, L. Shi, S. Li, L. Xu, W. Qin, and H. Wang, "Urbanrural disparities in hypertension prevalence, detection, and medication use among Chinese Adults from 1993 to 2011," International Journal for Equity in Health, vol. 16, no. 1, article no. 50, 2017.

[24] M. Hosseini, M. Yousefifard, M. Baikpour et al., "Twenty-year dynamics of hypertension in Iranian adults: age, period, and cohort analysis," Journal of the American Society of Hypertension, vol. 9, no. 12, pp. 925-934, 2015. 


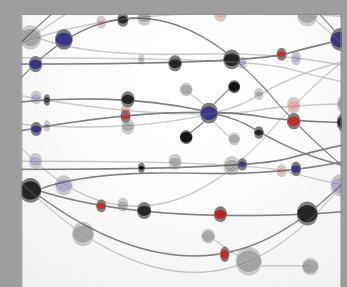

The Scientific World Journal
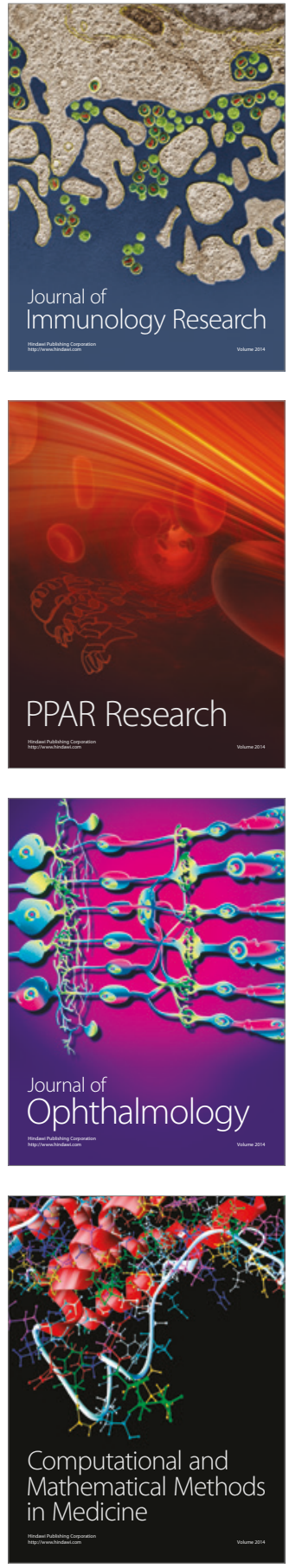

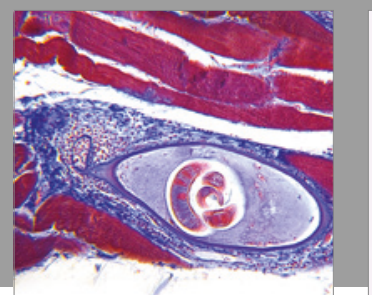

Gastroenterology Research and Practice
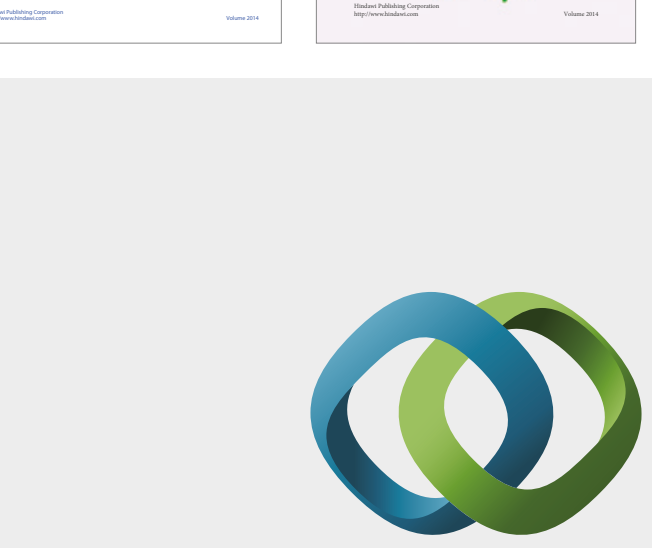

\section{Hindawi}

Submit your manuscripts at

https://www.hindawi.com
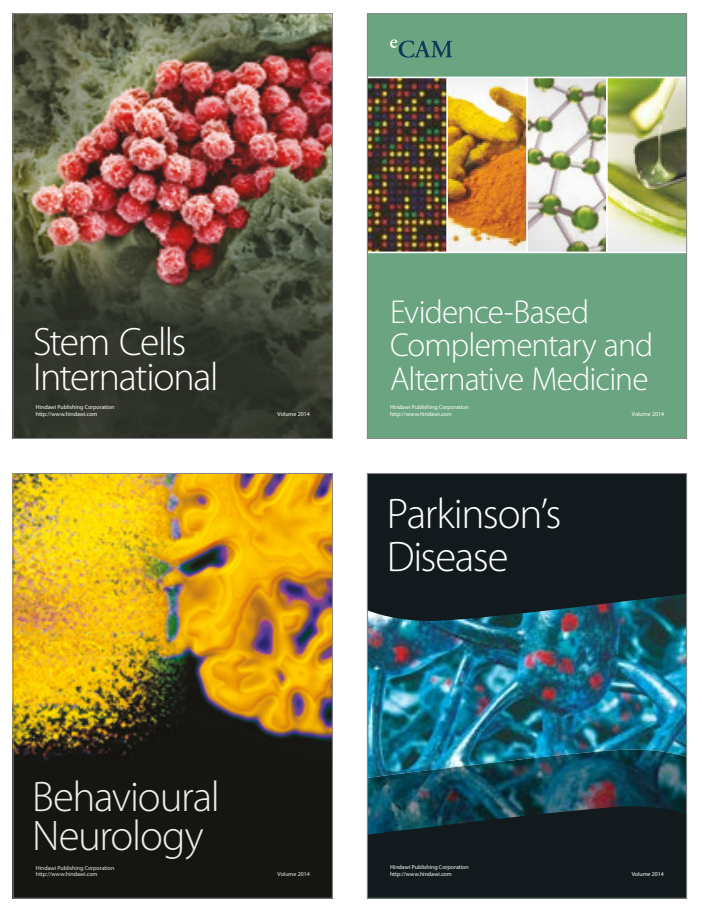
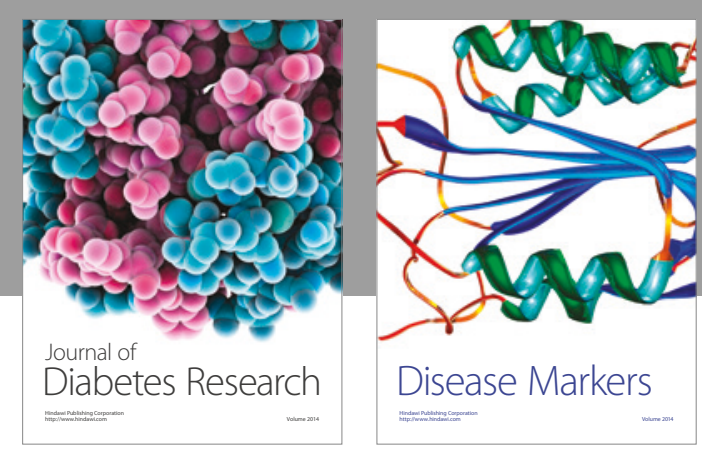

Disease Markers
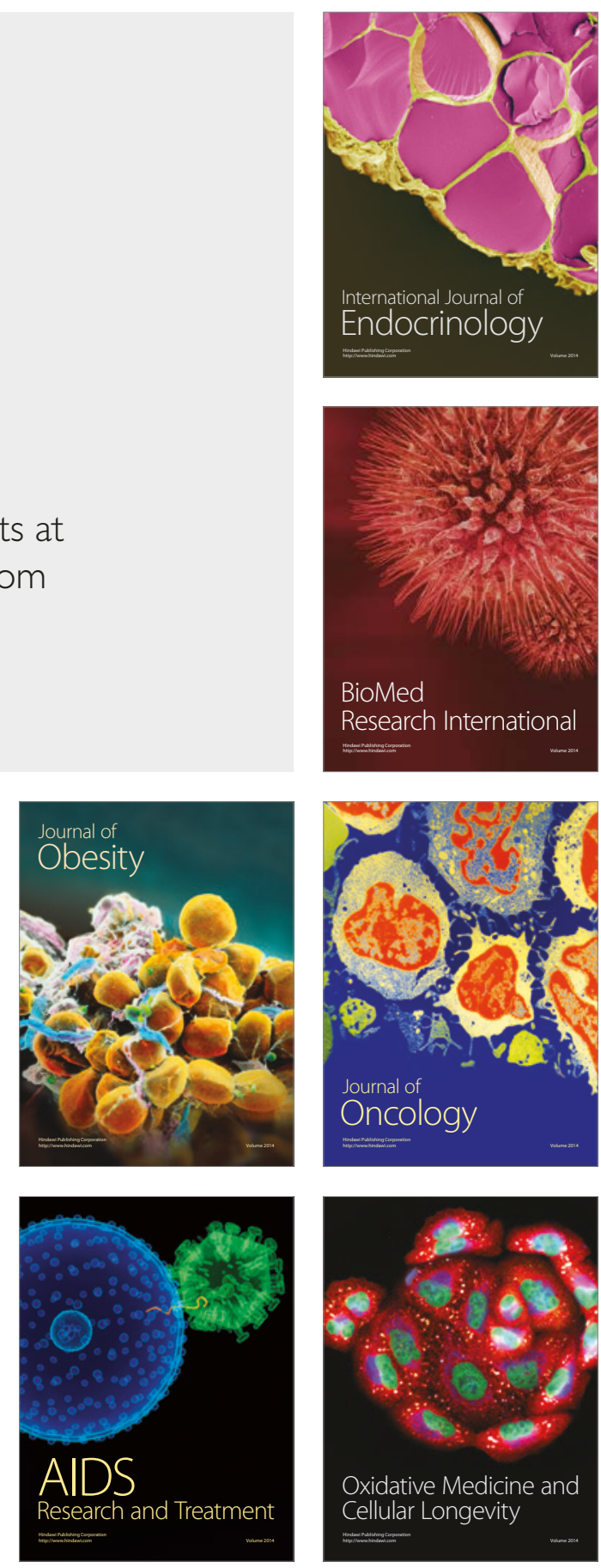